\title{
Accelerated Lipofuscinosis and Ubiquitination in Granulin Knockout Mice Suggest a Role for Progranulin in Successful Aging
}

\author{
Zeshan Ahmed, ${ }^{*}$ Hong Sheng, ${ }^{*}$ Ya-fei Xu, ${ }^{*}$ \\ Wen-Lang Lin, ${ }^{*}$ Amy E. Innes, ${ }^{*}$ Jennifer Gass, ${ }^{*}$ \\ Xin Yu, * Harold Hou, ${ }^{*}$ Shuichi Chiba, ${ }^{\dagger}$ \\ Keitaro Yamanouchi, ${ }^{\dagger}$ Malcolm Leissring, ${ }^{*}$ \\ Leonard Petrucelli, ${ }^{,}$Masugi Nishihara, ${ }^{\dagger}$ \\ Michael L. Hutton, ${ }^{*}$ Eileen McGowan, ${ }^{*}$ \\ Dennis W. Dickson, ${ }^{*}$ and Jada Lewis* \\ From the Department of Neuroscience," Mayo Clinic College of \\ Medicine, Jacksonville, Florida; and the Department of \\ Veterinary Physiology, ${ }^{\dagger}$ Veterinary Medical Science, University of \\ Tokyo, Tokyo, Japan
}

Progranulin (PGRN) is involved in wound repair, inflammation, and tumor formation, but its function in the central nervous system is unknown. Roles in development, sexual differentiation, and long-term neuronal survival have been suggested. Mutations in the GRN gene resulting in partial loss of the encoded PGRN protein cause frontotemporal lobar degeneration with ubiquitin immunoreactive inclusions. We sought to understand the neuropathological consequences of loss of PGRN function throughout the lifespan of $G R N$-deficient $\left(^{-/+}\right.$and $\left.{ }^{-/-}\right)$mice. An aged series of $G R N$-deficient and wild-type mice were compared by histology, immunohistochemistry, and electron microscopy. Although $G R N$-deficient mice were viable, $G \boldsymbol{R N}^{-1-}$ mice were produced at lower than predicted frequency. Neuropathologically, $G R N^{-/+}$ were indistinguishable from controls; however, $G R N^{-/-}$mice developed age-associated, abnormal intraneuronal ubiquitin-positive autofluorescent lipofuscin. Lipofuscin was noted in aged $G R N^{+/+}$mice at levels comparable with those of young $G \mathrm{RN}^{-/-}$mice. $G R N^{-1-}$ mice developed microgliosis, astrogliosis, and tissue vacuolation, with focal neuronal loss and severe gliosis apparent in the oldest $G R N^{-/-}$mice. Although no overt frontotemporal lobar degeneration with ubiquitin immunoreactive inclusions type- or TAR DNA binding protein-43-positive lesions were observed, robust lipofuscinosis and ubiquitination in $G \mathrm{RN}^{-1-}$ mice is strikingly similar to changes associated with aging and cellular decline in humans and animal models. Our data suggests that PGRN plays a key role in maintaining neuronal function during aging and supports the notion that PGRN is a trophic factor essential for long-term neuronal survival. (Am J Pathol 2010, 177:311-324; DOI: 10.2353/ajpath.2010.090915)

Progranulin (PGRN) is a 593-amino acid cysteine-rich protein that is heavily glycosylated. ${ }^{1}$ Encoded by a single gene (GRN) on human chromosome 17q21, PGRN contains seven granulin-like domains, which consist of highly conserved tandem repeats of a rare 12-cysteinyl motif. 2,3 PGRN is secreted and proteolytically cleaved by extracellular proteases giving rise to smaller peptide fragments termed granulins (GRNs). ${ }^{1}$ Full-length PGRN and its proteolytically derived GRNs are biologically active with distinct properties. In the periphery PGRN and GRNs have been implicated in wound repair, inflammation, tumor formation, and trophic support. ${ }^{4,5}$

PGRN has gained the attention of the neuroscience community with the recent discovery that mutations in GRN cause autosomal-dominant forms of frontotemporal lobar degeneration with ubiquitin-immunoreactive inclusions (FTLD-U). ${ }^{6,7}$ Pathogenic mutations in GRN mostly create null alleles, with premature termination of the coding sequence and nonsense-mediated decay of the mutant mRNA, resulting in haploinsufficiency of the protein. ${ }^{6}$ Recent studies have confirmed that patients with GRN

Supported by Mayo Alzheimer's Disease Research Center (grant P50AG16574 to E.M.) and American Health Assistance Foundation (grant A2009-013 to M.L.), Japan Society for the Promotion of Science (grantin-aid for scientific research 20248030 to M.N.), and Mayo Foundation (M.L., L.P., M.L.H., E.M., D.W.D., and J.L.).

Accepted for publication March 11, 2010.

Supplemental material for this article can be found on http://ajp. amjpathol.org.

Address reprint requests to Dennis W. Dickson, M.D., Mayo Clinic, 4500 San Pablo Rd., Jacksonville, FL 32224. E-mail: dickson.dennis@ mayo.edu. 
mutations have significantly reduced levels of PGRN, at least in their plasma and in lymphoblastoid cells derived from mutation carriers. ${ }^{8-10}$

Neuropathologically, FTLD-U (both with and without GRN mutations) is characterized by ubiquitin-positive intracytoplasmic and sometimes intranuclear neuronal inclusions. ${ }^{11}$ The major constituent of these inclusions in the majority of cases is a seemingly unrelated protein, TAR DNA binding protein-43 (TDP-43). ${ }^{12}$ In affected neurons, TDP-43 is absent from its normal nuclear location and forms ubiquitinated and hyperphosphorylated aggregates in the cytoplasm. The neocortex, hippocampus, amygdala, and basal ganglia seem to be most vulnerable to ubiquitin/TDP-43-positive inclusions and are often associated with atrophy, severe neuronal loss, gliosis, and tissue vacuolation. ${ }^{11,13}$ Despite these recent discoveries, how PGRN haploinsufficiency in FTLD-U with GRN mutations results in redistribution and aggregation of TDP-43 and neurodegeneration is currently unknown.

Little is known about the role of PGRN in the central nervous system (CNS). The expression of PGRN is regulated during CNS development, ${ }^{1}$ and in the adult CNS, PGRN is expressed in neurons and microglia ${ }^{6,14-16}$ with low or no expression in other glial cells. Consistent with its known functions in the periphery and cell type expression in the CNS, PGRN has also been implicated as a neurotrophic factor for long-term neuronal survival ${ }^{4,16,17}$ and is increased in the inflammatory response to CNS injury, infection, and neurodegeneration. ${ }^{4}$

Kayasuga and colleagues ${ }^{18,19}$ used gene targeting to knock out the murine GRN gene and demonstrated that PGRN was important for establishing some sexual dimorphic behaviors. Surprisingly, these mice were viable without any obvious disorders in reproductive function, suggesting that PGRN was not a critical factor for fertilization and development. Subsequently, it was suggested that the volumetric difference in the locus ceruleus of progranulin-deficient mice compared with controls was a possible cause of sexually dimorphic anxiety. ${ }^{20}$ Given that progranulin deficiency in humans leads to FTLD-U, it was surprising that C-terminal cleavage products of the TDP-43 protein that are characteristic for human FTLD-U were not observed in these progranulin-deficient mice. ${ }^{21}$

The objective of the current study was to characterize an aged series ( $1,7,12$, and 23 months) of GRN-deficient $\left(^{-/+}\right.$and $\left.{ }^{-1-}\right)$ mice to determine the neuropathological consequences of having partial or complete loss of PGRN function throughout life as a means to understand the biological role of PGRN in the CNS. Despite a partial loss of PGRN protein expression reminiscent of that seen in FTLD-U, GRN ${ }^{-1+}$ mice were neuropathologically identical to wild-type controls. In contrast, $G R N^{-1-}$ mice, which completely lacked PGRN protein, exhibited a progressive neuropathological phenotype consistent with accelerated aging, suggesting a novel role for PGRN in successful aging.
Table 1. Genotypes, Ages, and Sex Distribution of Mice Used for Neuropathological Characterization

\begin{tabular}{cccc}
\hline Age & $G R N^{+/+}$ & $G R N^{+/-}$ & $G R N^{-/-}$ \\
\hline 1 month & $4(2)$ & $4(1)$ & $5(3)$ \\
7 month & $6(3)$ & $5(3)$ & $5(4)$ \\
12 month & $6(4)$ & $6(3)$ & $5(3)$ \\
23 month & $3(3)$ & $3(2)$ & $3(1)$ \\
\hline
\end{tabular}

Numbers in parentheses are numbers of males.

\section{Materials and Methods}

\section{Gene Targeted Mice}

Generation of PGRN-deficient mice through targeted disruption of the GRN gene has been reported previously. ${ }^{19}$ PGRN-deficient mice were provided to the Mayo Clinic (E.M.) from M.N. (University of Tokyo), and the colony was expanded and maintained on a C57BL/6 background (The Jackson Laboratory, Bar Harbor, ME). Genomic DNA was obtained by tail biopsy at 21 days and assessed for the knockout and wild-type alleles by PCR. The primer sets 5'-CCAATATGGGATCGGCCATTGAAC-3' and 5'-CGCTCGATGCGATGTTTCGCTTGG-3' and 5'-GTGAAGTGCGACATGGAGGT-3' and 5'-CGCAGGTTCCTTTCTCTGTG-3' were used to detect gene-targeted and wild-type alleles, respectively. Mice were euthanized for tissue harvest at 1 , 7, 12, and 23 months (Table 1). All rodent specimens were obtained from animals handled by procedures approved by the Mayo Clinic Institutional Animal Care and Use Committee.

\section{Tissue Preparation}

Brains were rapidly removed from the skull, fixed in 10\% formalin, and dissected in the coronal plane for processing and paraffin embedding. Paraffin-embedded tissue was sectioned at a thickness of $5 \mu \mathrm{m}$ and mounted on glass slides. For all staining procedures, sections were deparaffinized in xylenes and rehydrated in a graded series of ethanol (100100, and 95\%) followed by distilled $\mathrm{H}_{2} \mathrm{O}$.

\section{Histology}

H\&E staining and Luxol fast blue-periodic acid Schiffhematoxylin (LFB-PAS) staining ${ }^{22}$ was performed on paraffin sections.

\section{Immunohistochemistry}

Immunohistochemistry $(\mathrm{IHC})$ was performed using primary antibodies detailed in Table 2. For the purpose of antigen retrieval, deparaffinized and rehydrated sections were heated in $200 \mathrm{ml}$ of distilled $\mathrm{H}_{2} \mathrm{O}$ using a preheated steamer (HS900, Black and Decker, Shelton, CT) for 30 minutes and allowed to cool in fresh distilled $\mathrm{H}_{2} \mathrm{O}$. For caspase-3 immunolabeling, antigen retrieval was performed in $200 \mathrm{ml}$ of low $\mathrm{pH}$ target retrieval solution $(\mathrm{pH}$ 6.1, DAKO, Carpinteria, CA). To maintain staining consistency, immunolabeling was performed using the 
Table 2. Details of Primary Antibodies Used for Immunohistochemistry

\begin{tabular}{lllll}
\hline Antibody & \multicolumn{1}{c}{ Epitope/antigen } & Species & Dilution & \\
\hline mPGRN & Mouse progranulin & Sheep & $1: 600$ & R\&D Systems, Minneapolis, MN \\
MAB1510 & Ubiquitin & Mouse & $1: 60 \mathrm{~K}$ & Chemicon, Temecula, CA \\
TDP-43 & TAR DNA binding protein-43 & Rabbit & $1: 3 \mathrm{~K}$ & Proteintech Group, Chicago, IL \\
IBA-1 & lonized calcium-binding adapter-1 & Rabbit & $1: 3 \mathrm{~K}$ & Wako Pure Chemicals (Tokyo, Japan) \\
CAIl & Carbonic anhydrase II & Rabbit & $1: 1 \mathrm{~K}$ & Ref. 23 \\
GFAP & Glial fibrillary acidic protein & Rabbit & $1: 2.5 \mathrm{~K}$ & Biogenex, San Ramon, CA \\
Asp175 & Cleaved caspase-3 & Rabbit & $1: 100$ & Cell Signaling, Danvers, MA \\
\hline
\end{tabular}

DAKO Autostainer according to the manufacturer's instructions using a DAKO EnVision+ System peroxidase kit, with 3,3'-diaminobenzidine (DAB) as the chromogen (DAKO) as described previously. ${ }^{24}$ For PGRN immunostaining, sections were incubated in primary antibody for 60 minutes, followed by 30 minutes of incubation with rabbit anti-sheep IgG antibody (BA-6000, Vector Laboratories, Burlingame, CA) to amplify the staining signal, before the standard immunostaining protocol was resumed. This double amplification immunohistochemical staining for progranulin has not been used previously. After immunostaining, sections were briefly counterstained with hematoxylin and coverslipped.

\section{Terminal Deoxynucleotidyl Transferase dUTP-X Nick-End Labeling Staining}

Terminal deoxynucleotidyl transferase dUTP-X nick end labeling (TUNEL) was used to detect 3 '-hydroxy termini of DNA strand breaks, using an ApopTag Plus Peroxidase In Situ Apoptosis Kit (Millipore, Billerica, MA) according to the manufacturer's instructions. 3,3'-Diaminobenzidine was used as the chromogen, and sections were counterstained with methyl green. Tonsil was used as a positive control.

\section{Autofluorescence}

To demonstrate autofluorescence, deparaffinized and rehydrated sections were coverslipped using Vectashield mounting medium containing 4',6-diamidino-2-phenylindole (Vector Laboratories) and viewed under a fluorescence microscope. Autofluorescence in histologically and IHC stained sections was also visible with fluorescence microscopy.

\section{Immunoelectron Microscopy}

For ultrastructural analysis by immunoelectron microscopy, mice ( 7 months) were perfused with $0.9 \%$ saline followed by $4 \%$ paraformaldehyde in $0.1 \mathrm{~mol} / \mathrm{L}$ of phosphate buffer. Brains were removed and immersed in the same fixative overnight at $4^{\circ} \mathrm{C}$. Small pieces of the hippocampus (CA2-3; $1 \mathrm{~mm}^{3}$ ) were dehydrated in 30,50 , 70 , and $90 \%$ ethanol, infiltrated, and embedded in LR White resin (Polysciences, Warrington, PA). Ultrathin sections collected on Formvar-coated nickel grids were incubated in UBQ (a rabbit polyclonal antibody to ubiquitin, $1: 20)^{25}$ overnight at $4^{\circ} \mathrm{C}$, followed by secondary antibody conjugated with colloidal gold particles. The sections were stained briefly with uranyl acetate and lead citrate before examination with a Philips 208S electron microscope.

For standard electron microscopy, mice were perfused with $2.5 \%$ glutaraldehyde-2\% paraformaldehyde- 0.1 $\mathrm{mol} / \mathrm{L}$ cacodylate buffer. Brains were removed and immersed in the same fixative overnight at $4^{\circ} \mathrm{C}$. Sections containing the habenula were sampled in the coronal plane and fixed in $1 \%$ aqueous $\mathrm{OsO}_{4}$, followed by uranyl acetate. After dehydration in ethanols and propylene oxide, tissue was infiltrated and embedded in Epon 812. Thin sections were stained with uranyl acetate and lead citrate before examination.

\section{Qualitative and Semiquantitative Pathological Analysis}

Pathological analyses were conducted with the investigator blinded to genotypes. Regions of interest were outlined on four different coronal sections for qualitative and semiquantitative pathological analysis. Evaluation of neuronal loss, apoptosis, and TDP-43 pathology was qualitative. Neuronal loss was assessed on H\&E sections, and apoptosis was evaluated by caspase- 3 immunohistochemistry and TUNEL staining. Neuronal PGRN immunoreactivity, ubiquitin-positive granular cytoplasmic staining (GCS), and changes in microglial morphology were measured using semiquantitative scoring schemes (Supplemental Figures 1 to 3, see http://ajp.amjpathol. org). Before semiquantitative analysis, a scoring system was established by an experienced investigator (Z.A.). A reference picture was then captured for each score and each measure to serve as a guide for all experimental scores.

\section{Quantitative Pathological Analysis}

The levels of PGRN and the degree of astrogliosis (glial fibrillary acidic protein [GFAP]) were quantified by image analysis. Using a slide scanner (Aperio Technologies, Vista, CA), immunostained sections were converted into high-resolution digital images. ImageScope v.8 software (Aperio Technologies) was used to digitally delineate tissue, and the positive pixel count algorithm was calibrated to detect positive immunostaining based on the following parameters: hue value, 0.1 ; hue width, 0.5 ; and color saturation threshold, 0.22. Measures were expressed as a percentage of the total area analyzed (\% burden). 
The number of single and clustered vacuoles was counted using H\&E-stained sections of the CA2-3 region of the hippocampus at the level of the habenular nucleus; artifactual vacuoles around cells were excluded. Only the presence and absence of vacuoles was recorded in the habenular nucleus.

\section{Measurement of Progranulin Levels}

To quantify progranulin levels mRNA levels in cathepsin $D$ knockout mice ${ }^{26}$ and wild-type controls, TaqMan gene expression assays (Applied Biosystems, Foster City, CA) were used. In brief, total RNA was isolated from hemibrain of each mouse using TRIzol (Invitrogen, Carlsbad, CA) reagent and purified with a Pure Link RNA Mini Kit (Invitrogen) according to the manufacturer's suggestions. Three micrograms of total RNA was used to synthesize cDNA using a High Capacity cDNA Reverse Transcription Kit (Applied Biosystems). The PCR reactions contain $0.25 \mu \mathrm{l}$ of Assay 20X, $2 \mu \mathrm{l}$ of cDNA (1:50 dilution), $0.25 \mu$ l of diethyl pyrocarbonate- $\mathrm{H}_{2} \mathrm{O}$, and $2.5 \mu \mathrm{l}$ of Master Mix (Applied Biosystems). The assay identification number for eukaryotic 18S rRNA is Hs99999901_s1. The assay for mouse granulin is a custom TaqMan gene expression assay. The PCR reactions were run in triplicate in a 384-well plate on an ABI7900 system (Applied Biosystems): 1 cycle of $50^{\circ} \mathrm{C}$ for 2 minutes, 1 cycle of $95^{\circ} \mathrm{C}$ for 10 minutes, followed by 40 cycles of $95^{\circ} \mathrm{C}$ for 15 seconds and $60^{\circ} \mathrm{C}$ for 1 minute. The data were analyzed using RQ Manager 1.2 software (Applied Biosystems).

To measure progranulin protein expression in the context of another model of lipofuscinosis, cortices from wildtype and cathepsin D knockout mice (postnatal 26 days) were weighed and homogenized in $5 \mathrm{ml} / 100 \mathrm{mg}$ with coimmunoprecipitation buffer $(50 \mathrm{mmol} / \mathrm{L}$ Tris- $\mathrm{HCl}[\mathrm{pH}$ 7.4], 300 mmol/L NaCl, 5 mmol/L EDTA, 1\% Triton-X-100, $1 \%$ SDS, and $1 \mathrm{mmol} / \mathrm{L}$ phenylmethylsulfonyl fluoride, protease inhibitor cocktail, and phosphatase inhibitors I and II). Samples were centrifuged at $16,000 \times g$ for 30 minutes at $4^{\circ} \mathrm{C}$. Supernatants were collected and a BCA protein assay (Thermo Fisher Scientific, Waltham, MA) was performed; $50 \mathrm{mg}$ of protein from each sample was diluted in distilled $\mathrm{H}_{2} \mathrm{O}, 2 \times$ Tris-glycine SDS sample buffer (Invitrogen), and 5\% $\beta$-mercaptoethanol (SigmaAldrich) and heat-denatured for 5 minutes at $95^{\circ} \mathrm{C}$. Samples were separated on 4 to 20\% Tris-glycine gels (Invitrogen) and transferred to polyvinylidene difluoride membranes (Millipore). Membranes were blocked in 5\% milk in Tris-buffered saline-0.1\% Triton X-100 and incubated overnight in anti-mouse PGRN (1:500; R\&D Systems, Minneapolis, MN) or anti-glyceraldehyde-3-phosphate dehydrogenase (1:10,000; BioSource International, Camarillo, CA) at $4^{\circ} \mathrm{C}$. Membranes were incubated in horseradish peroxidase-conjugated secondary antibodies (1:2500, Jackson ImmunoResearch Laboratories, West Grove, PA) for 1 hour at room temperature and detected with enhanced chemiluminescence (PerkinElmer Life and Analytical Science, Waltham, MA).

\section{Statistical Analysis}

Statistical tests were performed using SigmaStat 3.5 software (Systat Software Inc., Chicago, IL). For statistical analysis, a $t$-test was used for pairwise comparison of parametric data and a Mann-Whitney test for nonparametric data. For more than three groups, one way analysis of variance (parametric) and analysis of variance on ranks (nonparametric) were used depending on whether ordinal or continuous variables were evaluated. Statistical significance was set at $P<0.05$.

\section{Results}

\section{Deviation from Mendelian Distribution in $\mathrm{GRN}^{-1-}$ Mice}

$G R N^{+/-}$mice were crossbred to generate $\mathrm{GRN}^{+/+}$, $\mathrm{GRN}^{+/-}$, and $\mathrm{GRN}^{-1-}$ mice, for which the expected Mendelian distribution is 25,50 , and $25 \%$, respectively. Contrary to Mendelian predictions, the frequency of $G_{R N^{-1-}}$ offspring was reduced (15.5\%, $N=17$ of 110 pups). Breeding between $G R N^{+/-}$and $G R N^{-1-}$ mice also resulted in a lower frequency of $\mathrm{GRN}^{-1-}$ offspring $(25 \%$, $N=3$ of 12 pups), deviating from the expected Mendelian frequency of $50 \%$. In addition to the altered Mendelian ratios of newborn pups, we observed that $6.5 \%$ of $G R N^{-1-}$ mice died by 2 months of age compared with $1.8 \%$ of $\mathrm{GRN}^{+/-}$and $0 \%$ of $G R N^{+/+}$mice. We noted that young adult $\mathrm{GRN}^{-1-}$ mice in their home cages seemed particularly sensitive to startle from conditions that would be considered normal in barrier housing and handling. No other behavioral abnormalities or impaired motor function was observed during normal handling of $\mathrm{GRN}^{-1-}$ mice. In an effort to reduce postnatal death, we reduced cage handling and observed a qualitative improvement in postnatal survival of $\mathrm{GRN}^{-1-}$ offspring from all breedings, regardless of parental genotype. Aged mice showed no difference in survival, regardless of genotype.

\section{PGRN Immunoreactivity is Consistent with Genotypes and Increased in Older Mice}

The relative levels of PGRN were detected by IHC and quantified by image analysis in a subset of mice. Consistent with genotypes, GRN ${ }^{-1-}$ mice had no PGRN immunoreactivity, whereas $G R N^{+/-}$mice had dramatically reduced PGRN levels compared with those of $G_{R N^{+/+}}$ mice (Figure 1, A-C). At 23 months, the mean PGRN burden when assessed across the brain was $1.5 \%$ for $\mathrm{GRN}^{+/+}$mice $(N=3)$ compared with $0.8 \%$ for $\mathrm{GRN}^{+/-}$ mice $(N=3)$, a significant reduction of $53.3 \%(P<0.05)$; a similar pattern was also seen at 7 and 12 months (Figure 1D). PGRN immunoreactivity was largely constant at the 7- and 12-month time points but was significantly increased at 23 months in both $\mathrm{GRN}^{+/-}$and $\mathrm{GRN}^{+/+}$ mice $(P<0.05)$. Small sample size precluded genderbased statistical analysis. Qualitatively, no differences 
A
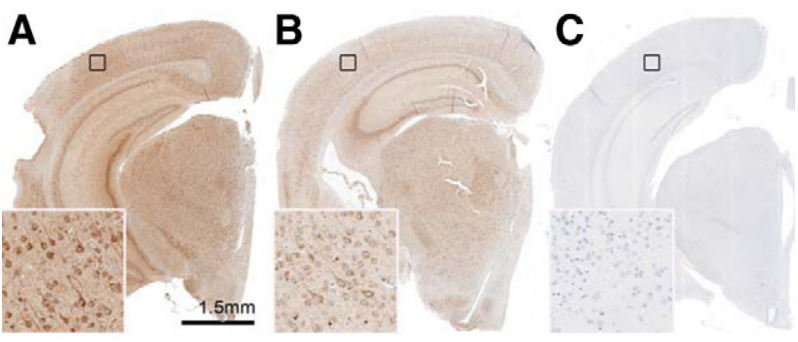

D

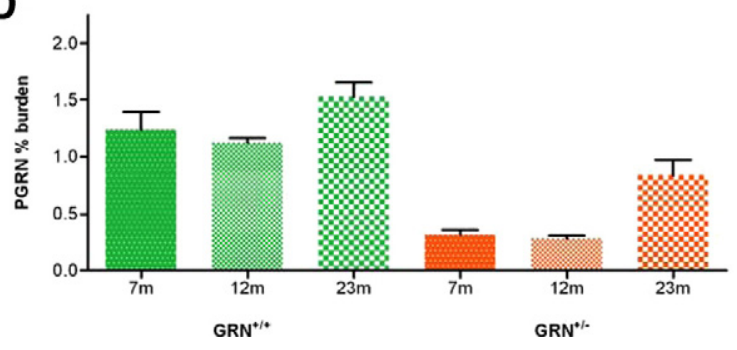

Figure 1. PGRN immunoreactivity is reflective of genotypes and increases in older $G R N^{+/+}$and $G R N^{+/-}$mice. As shown in 12-month-old mice, $G R N^{+/+}$mice (A) have higher PGRN immunoreactivity than $G R N^{+/}$mice (B), whereas $G R N^{-1-}$ mice (C) have no detectable PGRN expression. Higher magnification insets correspond to the areas identified by black squares. $\mathbf{D}$ : In a subset of $G R N^{+/+}$(green) and $G R N^{+/-}$(orange) mice, PGRN immunoreactivity was quantified by image analysis. Consistent with genotypes, $G R N^{+/-}$mice had significantly reduced PGRN levels compared with $G R N^{+/+}$ mice, at all ages $(P<0.05)$. An increase in PGRN immunoreactivity was also detected in 23-month-old $G R N^{+/+}$and $G R N^{+/-}$mice compared with 7- and 12-month-old mice of the same genotype $(P<0.05) . N=$ at least three for each group. Error bars $=$ SEM. Scale bar $=1.5 \mathrm{~mm}$.

were observed in the distribution or levels of PGRN between male and female mice (data not shown); however, sexually dimorphic nuclei were not specifically sampled.

\section{Distribution of PGRN Immunoreactivity in Mouse Brain}

Consistent with previous reports, PGRN was detected in neurons and microglia, 4,6 but PGRN IHC also labeled cells with the morphology and distribution of astrocytes, oligodendroglia, endothelia, and ependymal cells (data not shown). The intensity of staining was greatest in microglia and neurons, with the latter showing variations in regional distribution. In 12-month-old $G R N^{+/+}$mice, the intensity of PGRN immunostaining was greatest in the hippocampus (CA2-4) and thalamus and lowest in smaller neurons in the striatum (Supplemental Figure 1 and Supplemental Table 1, see http://ajp.amjpathol.org). A similar regional distribution pattern was observed for 12-month-old $\mathrm{GRN}^{+/-}$mice.

\section{Age-Associated Neuronal Ubiquitin Staining is Increased in $\mathrm{GRN}^{-1-}$ Mice}

Given that PGRN deficiency in humans was initially characterized by ubiquitin-positive neuronal inclusions, ${ }^{6,7}$ ubiquitin-IHC was performed in GRN-deficient mice and age-matched controls. No differences in ubiquitin staining were detected in 1-month-old mice, but at 7 months, $\mathrm{GRN}^{-1-}$ mice were characterized by an increase in ubiquitin immunoreactivity compared with that in age- matched $\mathrm{GRN}^{+/+}$and $\mathrm{GRN}^{+/-}$mice. This increase in ubiquitin positivity corresponded to amorphous granular cytoplasmic staining (GCS) in neurons. The degree of GCS varied based on anatomical distribution, with neurons in the posterior thalamus, CA2-4 of the hippocampus, midbrain, and brainstem being consistently and severely affected in the 7-month-old $G R N^{-1-}$ mice. Consistent with these $\mathrm{IHC}$ results, increased levels of ubiquitin were observed in Western blots on total hippocampus from $\mathrm{GRN}^{-1-}$ mice versus controls (data not shown). Neurons throughout the cortex were not as severely or frequently affected, and neurons in the CA1 and dentate fascia of the hippocampus were free of GCS. To quantify these changes, the severity of GCS was analyzed using a semiquantitative scoring scheme (Supplemental Figure 2, see http://ajp.amjpathol.org), which was applied to neuronal populations in the hippocampus (CA2-4) (Figure 2, $\mathrm{A}-\mathrm{H})$, cortex, and thalamus; regional GCS scores were averaged to calculate an overall GCS score. Variable sampling of other anatomical regions precluded them from formal analysis and qualitatively descriptions were instead used.

Across the genotypes, GCS increased with age; however, the overall GCS score was significantly greater in 7-, 12-, and 23-month-old $G R N^{-1-}$ mice, compared with age-matched $\mathrm{GRN}^{+/+}$and $\mathrm{GRN}^{+/-}$mice (Figure 2I; $P<$ $0.001)$. No differences in overall GCS score were detected between $\mathrm{GRN}^{+/+}$and $\mathrm{GRN}^{+/-}$mice, at any age.

In $\mathrm{GRN}^{-1-}$ mice, GCS occurred at 7 months (Figure 2, $F$ and I) and was comparable with the severity of GCS in 23-month-old $\mathrm{GRN}^{+/+}$(Figure 2, D and I) and $\mathrm{GRN}^{+/-}$ mice (Figure 2l). In $\mathrm{GRN}^{+/+}$and $\mathrm{GRN}^{+/-}$mice, GCS occurred at 12 months (Figure 2I), which despite being less severe had a distribution pattern similar to that in age-matched $G R N^{-1-}$ mice (Supplemental Figure 4, see http://ajp.amjpathol.org); GCS was relatively more severe in thalamic and CA2-3 neurons than in CA4 and cortical neurons. The same pattern was also observed in the oldest (23 months) GRN ${ }^{-1-}$ mice (Supplemental Figure 5, see http://ajp.amjpathol.org), which had the highest overall GCS scores (Figure 2I). Despite the substantial involvement of some hippocampus regions, the CA1 (Supplemental Figure 5, see http://ajp.amjpathol.org) and dentate fascia neurons remained free of GCS even in the oldest $G R N^{-1-}$ mice.

\section{Neuronal Ubiquitin Immunoreactivity Corresponds to Lipofuscin Pigment}

Although the majority of cases of FTLD- $U$ with mutations in GRN are characterized by ubiquitin-positive and TDP43-positive intraneuronal inclusions, the $G R N^{-1-}$ mice did not show TDP-43 cytoplasmic redistribution (data not shown) or increased levels of TDP-43 phosphorylation up to 22 months of age with antibodies detecting phosphorylation at 409/410 of TDP-43 (Supplemental Figure 6, see http://ajp.amjpathol.org). TDP-43 immunoreactivity was present in the nucleus of neurons and glia, consistent with its normal cellular localization. ${ }^{27}$ 


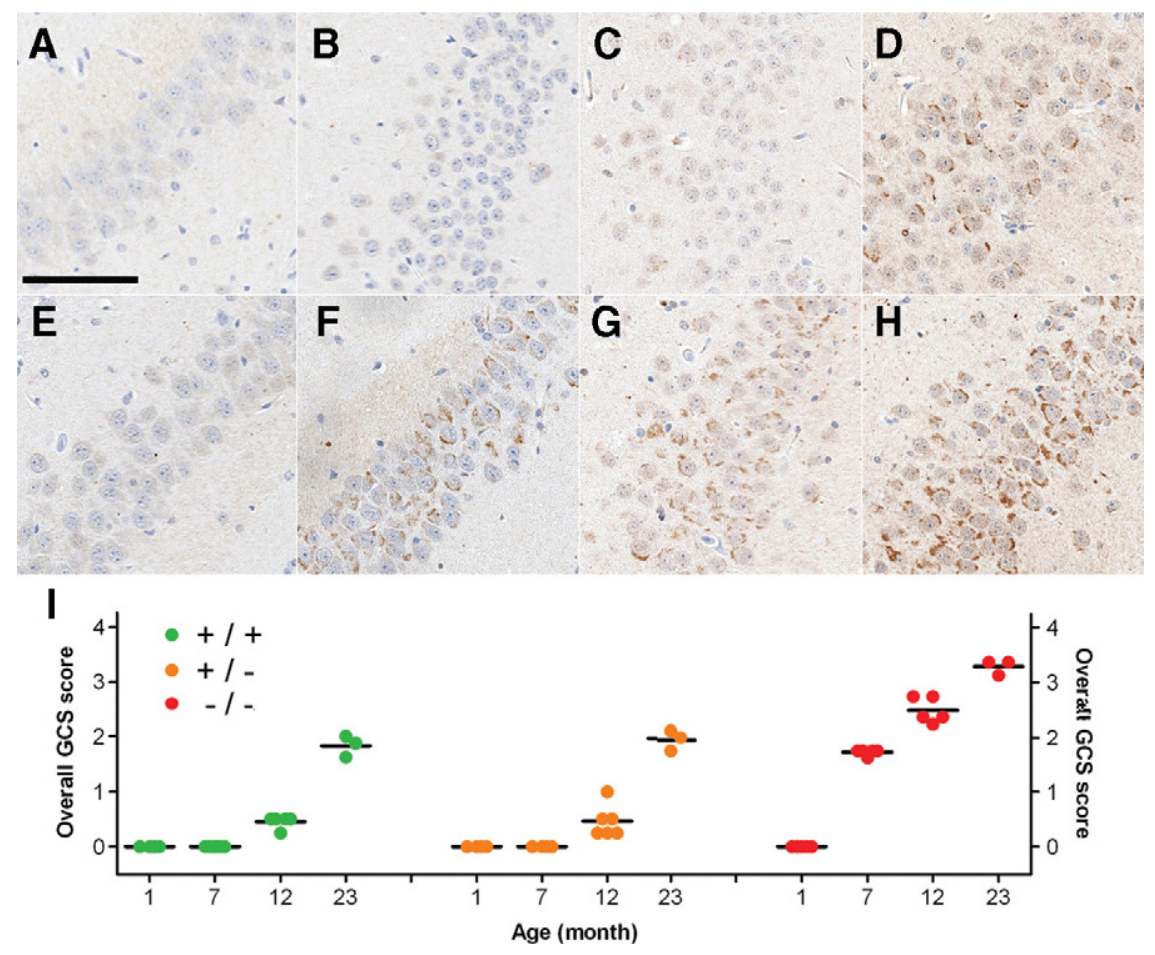

Figure 2. Age-associated increase in ubiquitinpositive GCS. Ubiquitin immunohistochemistry demonstrating the age-associated increase in GCS in the CA2-3 region of the hippocampus of $G R N^{+/+}(\mathbf{A}-\mathbf{D})$ and $G R N^{-/}(\mathbf{E}-\mathbf{H})$ mice, with the latter showing an accelerated increase in GCS. A and E: 1 month. B and F: 7 months. C and G: 12 months. $\mathbf{D}$ and $\mathbf{H}: 23$ months. $G R N^{+/+}$ and $G R N^{+/-}$showed no noticeable difference in GCS. I: A semiquantitative scoring scheme was used to measure the severity of GCS in key anatomical regions (Supplemental Figure 2, see http://ajp.amjpatbol.org) to calculate an overall GCS score (mean of regional scores) for each mouse (colored circles). Overall GCS scores increased with age in all groups $(P<0.001)$. They also indicated that GCS occurred earlier (seven months) and was more severe in $G R N^{-1}$ mice $(P<0.001$ for 7,12 , and 23 months $)$ compared with age-matched $G R N^{+/+}$and $G R N^{+/-}$mice The oldest $G R N^{-1}$ mice had the highest overall GCS score. Horizontal black bars, mean. Scale bar $=100 \mu \mathrm{m}$.

Interestingly, intracellular material with morphology and distribution identical to those of ubiquitin-positive GCS could be visualized in $G R N^{-/-}$mice compared with $G R N^{+/+}$mice by LFB-PAS staining and was highly autofluorescent (Figure 3, A-F), both of which are properties of lipofuscin-pigment. ${ }^{28}$ Ultrastructural analysis (immunoelectron microscopy) of CA2-3 neurons of the hippocampus in 7-month-old mice, confirmed increased lipofuscin granules in $\mathrm{GRN}^{-1-}$ mice compared with $\mathrm{GRN}^{+/+}$mice (Figure 3, G-H). Immunogold labeling with ubiquitin-specific antibodies decorated clusters of granules that had peripherally located vacuoles and a
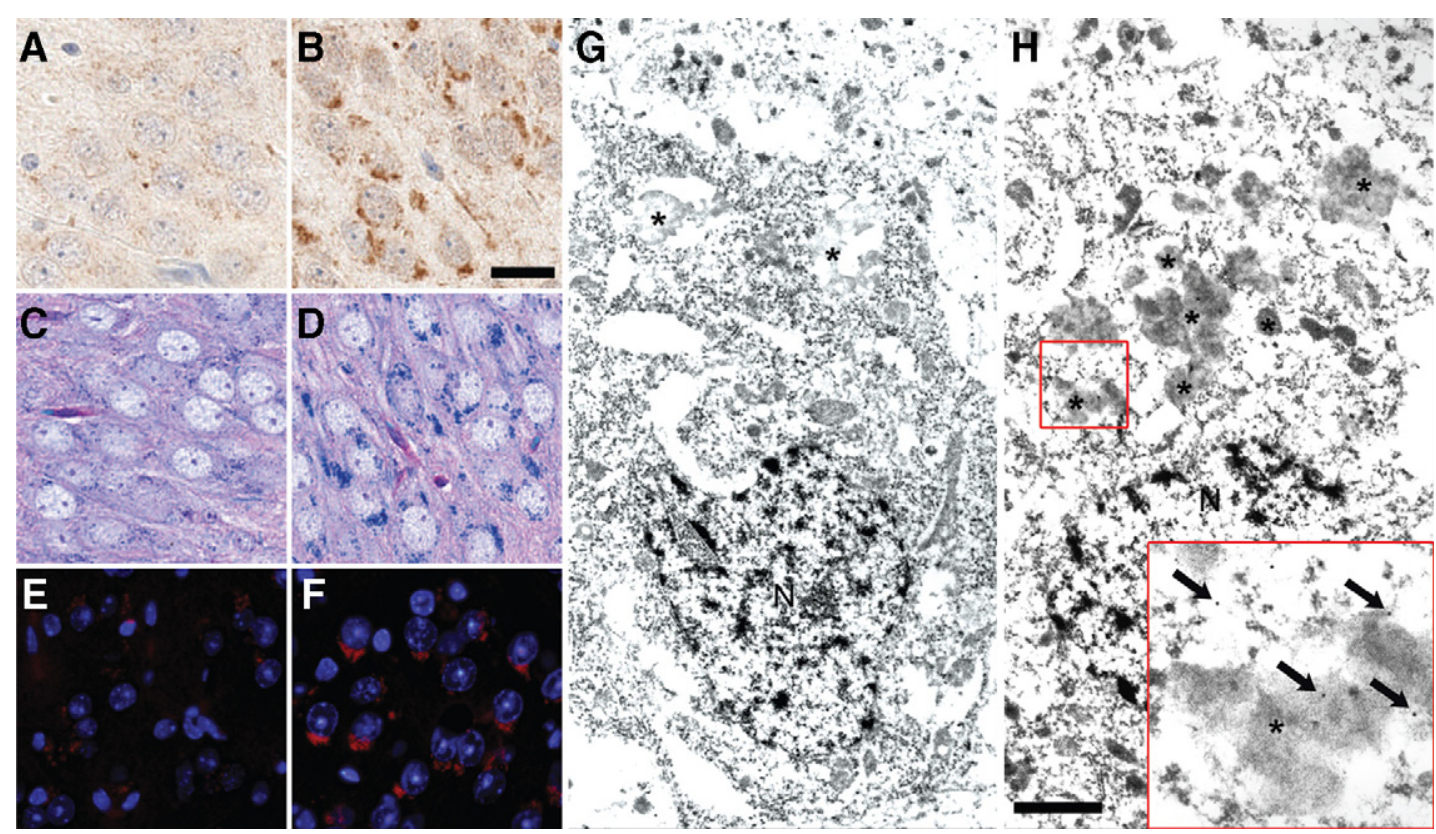

Figure 3. Histological and ultrastructural properties of neuronal, ubiquitin-positive GCS. Ubiquitin immunohistochemistry identified GCS in neurons of the hippocampus (CA2-3 region) were largely absent from 23-month-old $G R N^{+/+}$(A; shown) and $G R N^{+/-}$mice but were frequent in age-matched $G R N^{-1-}$ mice $(\mathbf{B})$. Unlike the $G R N^{++}$mice $(\mathbf{C}$ and $\mathbf{E})$, structures corresponding to GCS in $G R N^{-1}$ mice were also highlighted by LFB-PAS staining (D) and were autofluorescent (F) as shown by 4',6-diamidino-2-phenylindole staining viewed under a fluorescent microscope. These histological features are consistent with characteristics of lipofuscin. Ubiquitin-specific immunoelectron microscopy in 7-month-old mice confirmed the presence of lipofuscin granules (asterisk), which were qualitatively less numerous in CA2-3 neurons of $G R N^{+/+}$(G; shown) and $G R N^{+/-}$mice compared with $G R N^{-/}$mice (H). Higher magnification inset shows gold particles (arrows) decorating clusters of granules containing a heterogeneous mixture of electron-dense material, consistent with ultrastructural properties of lipofuscin. $\mathrm{N}$, nucleus. Scale bar: $25 \mu \mathrm{m} \mathbf{A}-\mathbf{F} ; 1 \mu \mathrm{m} \mathbf{G}$ and $\mathbf{H}$. 
heterogeneous mixture of dense material (Figure 3, $\mathrm{G}-\mathrm{H}$ ), consistent with lipofuscin. ${ }^{29}$ Furthermore, the number of lipofuscin-granules was noticeably higher in neurons of $\mathrm{GRN}^{-1-}$ mice compared with those of $G R N^{+/+}$and $G R N^{+/-}$mice (data not shown) to support light microscopic data suggesting that GCS (lipofuscin) accumulation occurred earlier and was more severe in $\mathrm{GRN}^{-/-}$mice.

\section{Vacuolation but No Overt Neuronal Loss in $\mathrm{GRN}^{-1-}$ Mice}

Qualitative examination of H\&E-stained sections, showed no overt neuronal loss in GRN-deficient mice compared with wild-type mice in either the brain or spinal cord. Consistent with this observation, markers of apoptosis such as caspase-3 and TUNEL did not differ between genotypes (data not shown), despite an in vitro study suggesting that abruptly decreasing PGRN expression with small interfering RNA in transfected cell lines results in caspase-3 activation. ${ }^{30}$ The oldest $G R N^{-1-}$ mice (23 months) had evidence of focal neuronal loss (described below), although this was not associated with apoptosis.

Although overt neuronal loss was not evident, histological studies of $G R N^{-1-}$ mice revealed vacuolation in the habenular nucleus and neuropil of the CA2-3 region of the hippocampus. Vacuoles could be separated into two major types: single or clustered vacuoles (Figure 4, A-C). In a blinded fashion, the presence or absence of vacuoles in the habenular nucleus was recorded, as was the number and type of vacuoles surrounding CA2-3 of the hippocampus; artifactual vacuoles around cells or vessels were excluded.

Regardless of genotype, none of the youngest mice (1 month) showed habenular vacuolation, but in older mice (7 to 23 months) microvacuolation segregated with the $G R N^{-1-}$ genotype and was absent in all $\mathrm{GRN}^{+/+}$and $G R N^{+/-}$mice $(P<0.001)$, even at 23 months of age (Figure 4, D-H). In $G R N^{-1-}$ mice, the habenula was mainly affected by single vacuoles and once present, their number did not seem to increase with age, although qualitatively their individual size was greater in older mice (Figure 4, A-B, D-F). The vacuolation was most severe in the ventromedial region of the habenula and was not associated with any noticeable neuronal loss. Ultrastructural analysis of the habenula by electron microscopy in a 23-month-old mouse (Supplemental Figure 7, see http://ajp.amjpathol. org) could not identify the exact nature of the large single vacuoles; however, this technique did identify intracellular vacuoles within neurons, oligodendrocytes, and astrocytes (data not shown), in addition to occasional axonal spheroids.

The neuropil of the CA2-3 region of the hippocampus contained both single and clustered vacuoles. The number of single vacuoles within this region increased with age, showing no genotype-based differences (data not shown). Although vacuole clusters were absent in the youngest mice (1 month), they were almost always present in older ( 7,12 , and 23 months) $G R N^{-1-}$ mice; whereas, they were rare and inconsistent in older $\mathrm{GRN}^{+/+}$and $\mathrm{GRN}^{+/-}$mice (Figure 4I; $P<0.05$ ). Col-

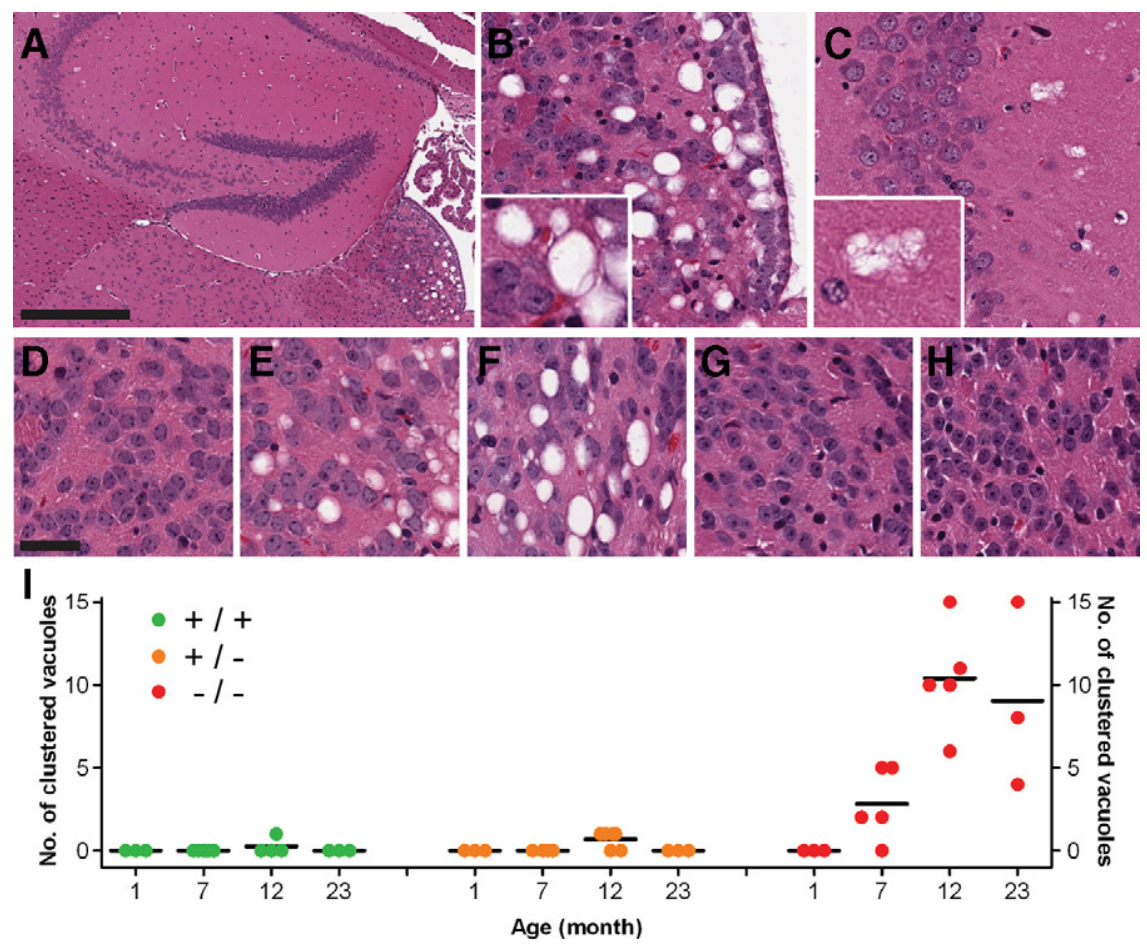

Figure 4. Abnormal tissue vacuolation in older $G R N^{\prime-}$ mice. H\&E staining identified vacuolation in the habenular nucleus (A and $\mathbf{B})$ and the neuropil surrounding CA2-3 regions (A and $\mathbf{C}$ ) of the hippocampus in older $G R N^{-/}$mice. The former was largely characterized by single vacuoles whereas the latter contained mainly clustered vacuoles (inset). In $G R N^{-1-}$ mice, habenular vacuolation was not present at 1 month (D) but was a consistent feature in older $G R N^{-}$ (E: 7 month; B: 12 month; F: 23 month] mice and absent in all $G R N^{+/+}(\mathbf{G})$ and $G R N^{+/-}$mice $(\mathbf{H})$ even at 23 months. I: Clustered vacuoles were counted in CA2-3 of the hippocampus, occurring in the majority of $G R N^{-1-}$ mice at seven months and becoming more frequent in 12- and 23month-old mice. These vacuoles were largely absent in $G R N^{+/+}$and $G R N^{+/-}$, but if present had a low frequency. Differences in the number of clustered vacuoles between $G R N^{-1-}$ mice and $G R N^{+/+}$or $G R N^{+/-}$mice were statistically significant for 7-, 12-, and 23-month-old mice $(P<$ $0.05)$. Horizontal black bars, mean. Scale bar: $400 \mu \mathrm{m} \mathrm{A} ; 30-\mu \mathrm{m} \mathbf{D}-\mathbf{H}$. 


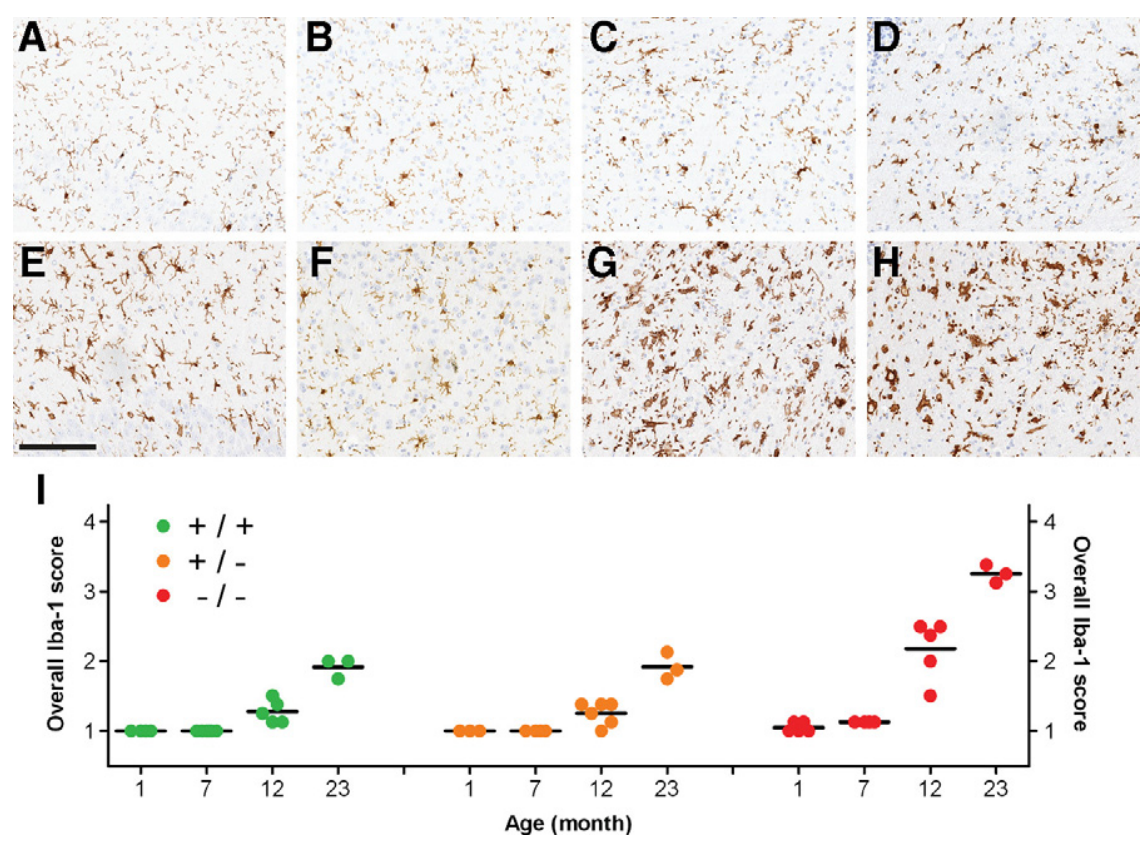

Figure 5. Changes in microglial morphology indicate increased microgliosis in $G R N^{-1-}$ mice. Regional examination of Iba-1-positive microglia in a 23-month-old $G R N^{+/+}$mouse showed a mixture of ramified and reactive microglia in the hippocampus CA2-3 region $(\mathbf{A})$ and cortex $(\mathbf{B})$ with predominately reactive microglia in the thalamus (C) and brainstem (D). In contrast, age-matched $G R N^{--}$mice contained mainly amoeboid microglia in the hippocampus (E), reactive microglia in the cortex $(\mathbf{F})$, and phagocytic microglia in the thalamus (G) and brainstem $(\mathbf{H}) . G R N^{+/-}$mice (not shown) were indistinguishable from age-matched $G R N^{+/+}$mice. I The morphology of Iba-1-positive microglia was scored in key anatomical regions (Supplemental Figure 3, see bttp://ajp.amjpathol.org) and averaged to generate an overall Iba-1 score for each mouse (individual circles). Overall Iba-1 scores were comparable across genotypes at one month of age; however, at 7, 12 and 23 months of age, $G R N^{--}$mice had significantly higher scores $(P<0.001)$ compared with age-matched $G R N^{+/+}$and $G R N^{+/-}$mice. Overall Iba-1 scores for 23-month-old $G R N^{+/+}$and $G R N^{+/-}$mice was comparable with that of 12-month-old $G R N^{-1-}$ mice, whereas the oldest $G R N^{-1-}$ mice (23 months) had the highest overall Iba-1 score. Overall Iba-1 scores increased with age in all genotypic groups $(P<0.001)$. Horizontal black bars, mean; Iba-1 scores: 1 , ramified; 2 , reactive 3, amoeboid; 4, phagocytic. Scale bar $=150 \mu \mathrm{m}$. lectively, habenular vacuolation and clustered vacuoles in the hippocampus were specific for older $G R N^{-1-}$ mice.

\section{Increased Gliosis in GRN ${ }^{-1-}$ Mice May Be an Early Sign of Neurodegeneration}

To investigate microgliosis, the morphology of ionized calcium-binding adaptor molecule 1 (lba1)-positive microglia $^{24}$ was analyzed in the brainstem, thalamus, hippocampus (CA2-3), and cortex of GRN-deficient and control mice (Figure 5). In young $\mathrm{GRN}^{+/+}$and $\mathrm{GRN}^{+/-}$ mice (up to 7 months), microglia had a ramified morphology in all regions of interest. By 12 months the brainstem, thalamus, and/or hippocampus contained a mixture of ramified and reactive microglia in these mice; the cortex still had only ramified microglia. The oldest GRN ${ }^{+/+}$(Figure 5, A-D) and $G R N^{+/-}$mice at 23 months typically contained a mixture of ramified and reactive microglia in the hippocampus and cortex and reactive microglia in the brainstem and thalamus (with occasional amoeboid microglia in the former). Note that phagocytic microglia were absent in all regions and at all ages in $G R N^{+/+}$and $\mathrm{GRN}^{+/-}$mice.

The youngest $G R N^{-1-}$ mice (1 month) also had ramified microglia in all regions of interest, but by 7 months, all of the $G R N^{-1-}$ mice had a mixture of ramified and reactive microglia in either the brainstem or thalamus. At 12 months, GRN ${ }^{-1-}$ mice had mainly amoeboid and occasional phagocytic microglia in the brainstem and thalamus but also a mixture of reactive and ramified microglia in the hippocampus and cortex. The oldest $G R N^{-1-}$ mice (23 months) contained mainly amoeboid microglia in the hippocampus and reactive microglia in the cortex with huge numbers of phagocytic microglia in the brainstem and thalamus (Figure 5, E-H). Across genotypes, the thalamus and brainstem were more vulnerable than the hippocampus and cortex to changes in microglial morphology.

To quantify these changes, microglial morphology was scored (Supplemental Figure 3, see http://ajp.amjpathol. org) and averaged across regions of interest (overall Iba-1 score) to provide a measure of microgliosis (Figure $5 \mathrm{l})$. Consistent with descriptions of microglial morphology, the overall Iba-1 score was significantly higher $(P<$ $0.001)$ in $G R N^{-1-}$ mice compared with $G R N^{+/+}$or $G R N^{+/-}$mice at 7, 12, and 23 months of age; no differences were identified between $\mathrm{GRN}^{+/+}$and $\mathrm{GRN}^{+/-}$ mice at any age. In each genotypic group, the overall Iba-1 score increased with age $(P<0.001)$; however, these changes occurred earlier and were more severe in $G R N^{-1-}$ mice. For example, overall Iba-1 scores for 12month $G R N^{-1-}$ mice were comparable with those of 23month-old $\mathrm{GRN}^{+/+}$or $\mathrm{GRN}^{+/-}$mice (Figure 5I). Although the density of microglia was not analyzed with image analysis, increases in the Iba-1 score were often associated with increases in microglia numbers.

To measure astrogliosis, the relative degree of GFAP immunoreactivity (\% burden) was determined by image analysis. Similar to the patterns observed for Iba-1-positive microglia, GFAP burden was i) consistently higher in the brainstem and thalamus than in the hippocampus and cortex (Figure 6, A-H), ii) significantly higher in $\mathrm{GRN}^{-1-}$ mice $(P<0.01)$ compared with $\mathrm{GRN}^{+/+}$or $G R N^{+/-}$, but only at 12 and 23 months of age (Figure 6I), and iii) increased with age $(P<0.001)$ in all genotypic groups (Figure 6l).

In summary, microgliosis as defined by changes in microglial morphology occurred earlier (7 months) and was more severe in $\mathrm{GRN}^{-1-}$ mice. Astrogliosis also occurred earlier and was more severe in $G R N^{-/-}$mice, but 

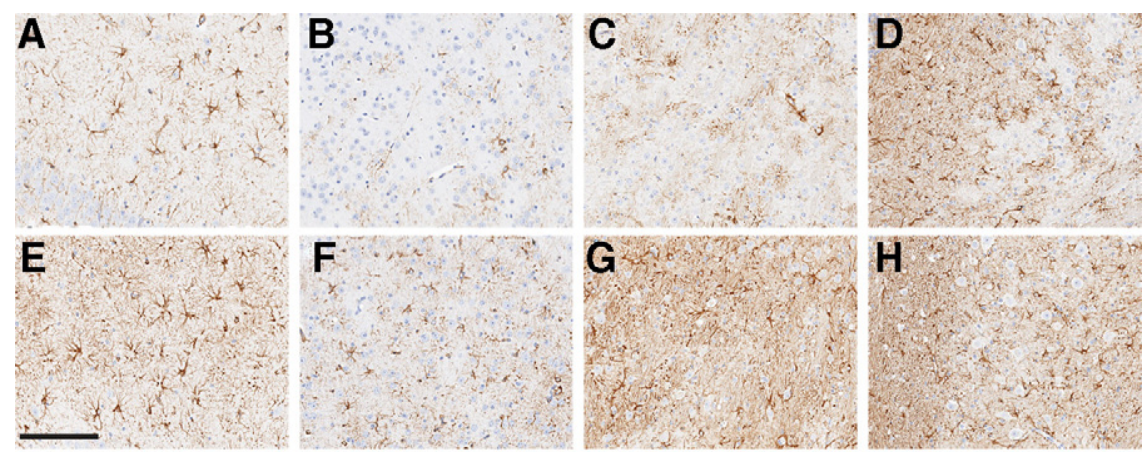

I

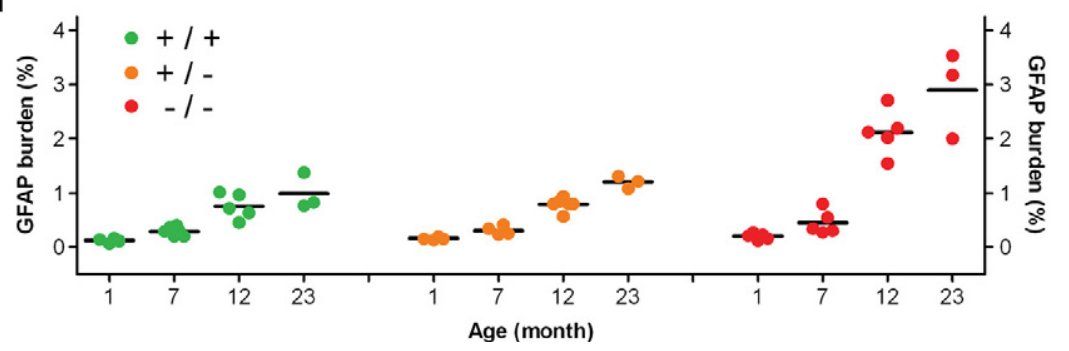

Figure 6. Increased astrogliosis in $G R N^{-1-}$ mice. The GFAP burden was comparatively lower in 23-month $G R N^{+/+}$and $G R N^{+/-}$(not shown) mice in the CA2-3 (A), cortex (B), thalamus (C), and brainstem (D) compared with age-matched $G R N^{-1}$ mice $(\mathbf{E}-\mathbf{H})$. The GFAP burden in $G R N^{-1}$ mice was greatest in the thalamus (G) and brainstem (H), with CA2-3 (E) and cortex (F) having a lower burden. In these same regions, the degree of astrogliosis was quantified by measuring GFAP immunoreactivity ( $\%$ burden) by image analysis for each mouse (individual circles, I). In younger mice (1-7 months), the mean GFAP burden (horizontal black bar) was similar among genotypic groups. Older $G R N^{-1}$ mice (12 and 23 months) had a significantly higher GFAP burden $(P<0.01)$ compared with age-matched $G R N^{+/+}$and $G R N^{+/-}$mice. The GFAP burden increased with age in all genotypic groups. Scale bar $=150 \mu \mathrm{m}$. these changes were not evident until 12 months. For both microgliosis and astrogliosis, the brainstem and thalamus were more vulnerable than the hippocampus and cortex. Note that the habenular nucleus, which demonstrated GRN ${ }^{-1-}$-specific vacuolation by 7 months (see above), did not show any genotype-specific differences in microgliosis or astrogliosis (data not shown).

\section{Focal Neuronal Loss and Extraneuronal Lipofuscin in the Oldest GRN ${ }^{-1-}$ Mice}

The oldest $G R N^{-1-}$ mice (23 months) were characterized by extensive lipofuscin accumulation and very severe gliosis, especially in the thalamus and hippocampus (CA2-3), regions that normally express high levels of neuronal PGRN (Supplemental Table 1, see http://ajp. amjpathol.org). Detailed examination of these regions in the oldest $G R N^{-1-}$ mice revealed further evidence of neurodegeneration.

In the oldest $\mathrm{GRN}^{+/+}$and $\mathrm{GRN}^{+/-}$mice, the CA2-3 region of the hippocampus was densely populated with neurons that were in close proximity to one another. In contrast, the oldest $G R N^{-1-}$ mice consistently had areas of the CA2-3 in which the neurons were more sparsely populated (SupplementalFigure8, seehttp://ajp.amjpathol. org). On adjacent sections stained for Iba-1 and ubiquitin, the same areas contained infiltrating reactive and amoeboid microglia and the surrounding neurons had extensive GCS, features that were absent in agematched $\mathrm{GRN}^{+/+}$and $G R N^{+/-}$mice (Supplemental Figure 8, see http://ajp.amjpathol.org). These areas of neuronal depletion and microgliosis in the oldest $G R N^{-1-}$ mice are likely to represent focal neuronal loss, possibly because of severe lipofuscin accumulation. Such qualitative observations of focal neuronal loss were only possible in the hippocampus because of the normally dense neuronal distribution.
Nevertheless, examination of Iba-1 staining in the thalamus by fluorescence microscopy (Supplemental Figure 9, see http://ajp.amjpathol.org) revealed that a subset of phagocytic microglia in the oldest $G R N^{-1-}$ mice contained autofluorescent lipofuscin pigment (black arrows), which seemed independent from neuronal lipofuscin deposits (white arrows). Astrocytes and oligodendroglia did not contain such autofluorescent material (Supplemental Figure 9, see http://ajp.amjpathol.org). In 12-month-old $\mathrm{GRN}^{-1-}$ mice, microglial lipofuscin was rare, and it was altogether absent in younger mice ( 1 to 7 months). Furthermore, none of the $G R N^{+/+}$and $G R N^{+/-}$mice contained microglial lipofuscin. Given the phagocytic morphology of lipofuscin-containing microglia and their rarity at younger ages, it is more likely that their lipofuscin was derived from the phagocytosis of dead or dying lipofuscin-containing neurons, rather than progressive endogenous accumulation.

In addition to neuronal and microglial lipofuscin in the oldest $G R N^{-1-}$ mice, a third pool of autofluorescent material was also identified (Supplemental Figure 9, see http://ajp.amjpathol.org). This particular material was pleomorphic in shape and size, was ubiquitinnegative, and did not seem to be associated with cellular membranes or nuclei; instead this material had a perivascular distribution and stained intensely purple (ie, metachromatic staining) by LFB-PAS (Supplemental Figure 9, see http://ajp.amjpathol.org). These potentially extracellular lipofuscin deposits were most common in the thalamus but were also present in the hippocampus (CA2-3 region) and brainstem; they were rare in the cortex. Similar to microglial lipofuscin, the extracellular lipofuscin was absent in younger $G R N^{-1-}$ mice (1 to 12 months) and other genotypic groups $\left(G R N^{+/+}\right.$and $\left.G R N^{+/-}\right)$. Perivascular lipofuscin had a distribution similar to that of neuronal lipofuscin and was absent in younger $G R N^{-1-}$ mice, suggesting that it may 
be a secondary consequence of focal neuronal loss similar to microglial lipofuscin.

\section{Increased Progranulin Levels in Response to Genetically Induced Lipofuscinosis}

To determine whether progranulin was increased in another model of lipofuscinosis, we examined progranulin expression in cathepsin D homozygous knockout mice, ${ }^{26}$ which develop rapid lipofuscinosis due to cathepsin D deficiency. Using quantitative real-time PCR TaqMan analysis to measure progranulin levels, we observed an almost $80 \%$ increase of progranulin mRNA $(P<0.005)$ in the cortices of cathepsin D knockout mice compared with wild-type controls (Supplemental Figure 10, see http://ajp.amjpathol.org). These results were confirmed by analysis of progranulin protein expression using Western blotting (Supplemental Figure 10, see http://ajp.amjpathol.org).

\section{Discussion}

Mutations in the human GRN gene have been shown previously to cause the neurodegenerative disease FTLD-U. ${ }^{6,7}$ In this study, we present the first detailed neuropathological analysis of GRN-deficient mice that mimic the genetic deficit found in human FTLD-U cases associated with GRN mutations. Interestingly, GRN ${ }^{+/-}$ mice express roughly $50 \%$ of the normal levels of PGRN, similarly to humans carrying GRN mutations; ${ }^{8-10}$ however, they were phenotypically indistinguishable from wild-type littermates. In contrast, $G R N^{-1-}$ mice that completely lacked PGRN were born at lower than expected Mendelian frequency compared with mice containing at least one wild-type allele. GRN ${ }^{-1-}$ mice are fertile, however, and yield moderately sized litters when crossbred to other $\mathrm{GRN}^{-1-}$ mice. Consistent with a previous report suggesting that PGRN is involved in both the establishment and progression of pregnancy, ${ }^{1}$ our data suggest that conceptuses that completely lack PGRN may have reduced viability compared with those with partial or no PGRN deficiency.

Initial studies using postmortem human CNS tissue have previously suggested that PGRN expression was restricted to neurons and microglia. ${ }^{4,6,16}$ In the current study, the use of a modified $\mathrm{IHC}$ protocol that incorporated an extra amplification step detected PGRN in cells with the distribution and morphology of astrocytes and oligodendroglia (among others), albeit at lower levels than those in neurons and microglia. The low-level expression in certain cell types is the likely explanation for failure to detect PGRN in astrocytes and oligodendroglia in a recent report that used a standard double immunofluorescence protocol. ${ }^{31}$ Interestingly, the amplified IHC protocol also detected a basal level of PGRN immunoreactivity throughout the CNS parenchyma, which might represent extracellular or secreted forms of PGRN and/or GRNs. This basal PGRN immunoreactivity is unlikely to be "background" or "nonspecific" staining because $\mathrm{GRN}^{-1-}$ mice stained alongside other mice completely lacked this low-level immunoreactivity (Figure 1, A and C). Collectively, these observations suggest that i) the $\mathrm{IHC}$ method for detecting PGRN in this study is more sensitive than those reported previously, ii) PGRN is expressed by the majority of, if not all, CNS cell types, and iii) the CNS may be exposed to a pool of extracellular PGRN or GRNs; these observations indicate a more important biological role for PGRN in the CNS. The current study also demonstrated that PGRN expression increased with age in both $\mathrm{GRN}^{+/-}$and $\mathrm{GRN}^{+/+}$mice, probably attributable to glial changes, suggesting a more prominent role for PGRN in aged brain. This result is compelling, given our neuropathological findings that are suggestive of accelerated aging in the absence of PGRN expression in $\mathrm{GRN}^{-1-}$ mice.

$G R N^{-1-}$ mice demonstrated a progressive accumulation of intraneuronal ubiquitin-positive aggregates reminiscent of those seen in FTLD-U. Yin et $\mathrm{al}^{32}$ recently published results from another granulin knockout mouse line, reporting phosphorylation of TDP-43 in the dentate gyrus and thalamus of aged granulin-deficient mice. In contrast to these results, we saw no evidence of TDP-43 redistribution, aggregation, or phosphorylation of TDP-43 within the brains of granulin-deficient mice up to 22 months with antibodies to the same epitope previously reported. ${ }^{32}$

Instead neuronal ubiquitin corresponded to lipofuscin pigment, as defined by its ultrastructural, histological, and autofluorescent properties. ${ }^{28,29}$ Lipofuscin (also known as aging pigment) is a complex aggregate of highly oxidized cross-linked proteins and lipids in lysosomes. ${ }^{33}$ The formation of lipofuscin is influenced by oxidative stress, mitochondrial repair mechanisms, and the efficiency of cellular degradation systems (proteaso$\mathrm{mal} /$ lysosomal). Once formed, lipofuscin seems to be resistant to proteasomal and lysosomal degradation and cannot be exocytosed ${ }^{34}$; therefore, lipofuscin is considered a cellular "wear and tear" pigment, which is a reliable maker of cellular aging in postmitotic cells such as neurons. The earlier and more rapid accumulation of lipofuscin suggests accelerated aging in neurons of $G R N^{-/-}$mice compared with $\mathrm{GRN}^{+/+}$and $\mathrm{GRN}^{+/-}$mice and indicates that PGRN may be required for successful postmitotic aging.

Although the mechanism by which PGRN (and/or GRNs) influences the rate of lipofuscin formation is beyond the scope of this study, ubiquitin positivity of lipofuscin suggests that cellular degradation systems may be compromised in $G R N^{-1-}$ mice. Dysfunction of cellular degradation systems may be a direct consequence of PGRN knockdown, because the suspected subcellular localization of PGRN is speculated to be endosomal and or lysosomal, ${ }^{4}$ placing it neatly into cellular degradation pathways. On the other hand,an indirect mechanism is also feasible because lipofuscin accumulation itself has the potential to inhibit cellular degradation processes.

The onset of neuronal lipofuscin accumulation was accompanied by vacuolation in the habenula and hippocampus. The cause of habenular vacuolation was unknown as it was not associated with noticeable neuronal loss or gliosis, but its absence at 1 month and segrega- 
tion with the $\mathrm{GRN}^{-1-}$ genotype suggest that it was not a developmental abnormality but part of a degenerative process related to the absence of PGRN. The high expression of PGRN in the habenula in control mice is also consistent with this hypothesis. Despite ultrastructural analysis in 23-month-old mice, the exact nature of the vacuoles remains elusive as identifiable cellular structures were no longer present. Intracellular vacuoles identified in surrounding neurons and glia may represent the early stages of vacuole development, which would indicate that loss of PGRN leads to intracellular dysfunction and eventual degeneration; the presence of axonal spheroids containing degenerating vacuoles would support this hypothesis. Anatomically, the habenula is a central component of the dorsal diencephalic conduction pathway that interconnects the limbic forebrain to the midbrain and hindbrain. ${ }^{35}$ The medial habenula, which was preferentially affected in GRN ${ }^{-1-}$ mice, receives major afferent innervation from the septum and efferent projections to the interpeduncular nucleus in the ventral midbrain. Interestingly, nuclei that have reciprocal connections with the septum, such as the hippocampus (itself afflicted by clustered vacuoles) and thalamus were also those noted to have particularly severe neuronal lipofuscinosis. The connectivity of the habenula to other affected regions suggests that vacuolation may be a surrogate marker of system- or circuit-specific neurodegeneration.

The oldest $\mathrm{GRN}^{-1-}$ mice, at 23 months of age, also provided compelling evidence of neurodegeneration, although further analysis of this time point using stereological techniques is needed for confirmation. Neuronal lipofuscinosis and gliosis were most severe in the oldest $G_{R N^{-1-}}$ mice. In addition, they had focal neuronal loss and extraneuronal lipofuscin deposits. The former was observed in areas of neuronal loss in the CA2-3 region of the hippocampus, which is typically a continuous band of densely packed neurons; as observed consistently in age-matched $\mathrm{GRN}^{+/-}$and $\mathrm{GRN}^{+/-}$mice. The same areas of focal neuronal loss were also associated with infiltrating reactive and activated microglia, which are considered to represent a sensitive marker of neuronal damage ${ }^{36,37}$ It is possible that focal neuronal loss was also present in other regions where neurons are not so densely packed but had extensive gliosis (eg, thalamus); however, this would again require detailed stereological studies. Although neuronal loss was not recognized in the thalamus, there was indirect evidence of possible neuronal loss in the form of microglial and extracellular lipofuscin deposits. These extraneuronal pools of lipofuscin could have originally accumulated within neurons over time and were then phagocytosed or expelled after neuronal cell death to form microglial and extracellular lipofuscin (Figure 7). Two pieces of evidence lend support to this hypothesis. First, unlike neuronal lipofuscin, which began accumulating at 7 months and increased with age, extraneuronal lipofuscin was not a progressive feature, being largely restricted to microglia with a phagocytic morphology, in the oldest $G R N^{-1-}$ mice. Second, extraneuronal lipofuscin had a distribution very similar to that in regions also suffering from severe neuronal lipofuscinosis.

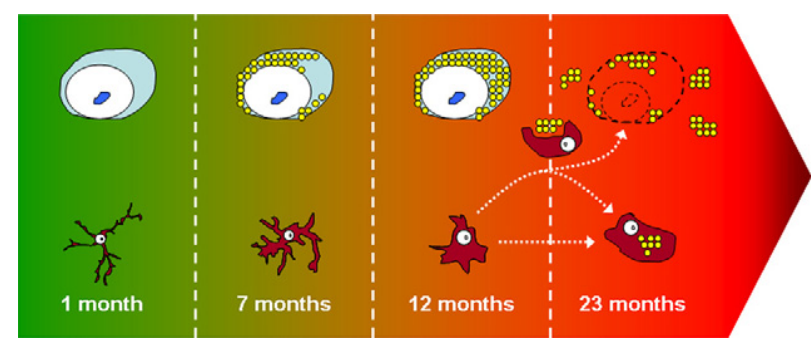

Figure 7. Hypothetical model of neurodegeneration based on the chronological appearance of pathology in $G R N^{-/}$mice. 1 month: young neurons are free of any pathology and microglia are in a ramified or resting state seven months: through an unknown mechanism, the lack of PGRN results in intraneuronal accumulation of lipofuscin pigment in aging neurons resulting in cellular stress which is detected by nearby microglia; 12 months: neuronal cytoplasm is full of lipofuscin pigment which adversely affects cellular function and long-term neuronal survival, signaling the activation of microglia; 23 months: slow and progressive loss of neurons, resulting in expulsion of neuronal lipofuscin into extracellular space, most of which is phagocytosed by activated microglia with some lipofuscin accumulating in the extracellular space. The lack of PGRN may also affect the normal function of activated microglia resulting in accumulation of endogenous microglial lipofuscin. A severe, sustained, and/or an inappropriate microglia (inflammatory) response (attributable to absence of microglial PGRN) may further enhance neuronal loss.

It is clear from the progressive accumulation of neuronal lipofuscin that PGRN is important in the normal aging process; however, if features of neurodegeneration in the oldest $\mathrm{GRN}^{-1-}$ mice are confirmed by stereological studies, it will also suggest that PGRN is essential for long-term neuronal survival, because its absence results in age-associated neurodegeneration, as defined by extensive gliosis, focal neuronal loss, and extraneuronal lipofuscin.

Neuronal lipofuscinosis along with its potential downstream consequences seemed to have a pattern of regional selective vulnerability in $\mathrm{GRN}^{-1-}$ mice. Of the anatomical regions of interest, the thalamus, CA2-3 of the hippocampus, and brainstem were affected earlier and more severely than cortical neurons. Interestingly, this pattern of vulnerability seems to inversely correlate with the normal relative degree of neuronal PGRN immunoreactivity, with the thalamus, hippocampus, and brainstem having higher neuronal expression than the cortex. This finding suggests that neurons that normally have high levels of PGRN expression are more susceptible to agerelated pathology, such as neuronal lipofuscinosis, in $G R N^{-1-}$ mice. Consistent with this hypothesis, large neurons in the striatum were shown to have higher PGRN expression than smaller neurons and in the oldest $G R N^{-1-}$ mice, neuronal lipofuscinosis was more severe in the former than in the latter (data not shown). Note that hippocampus CA1 and dentate neurons had moderate PGRN expression similar to that of cortical neurons but remained largely free of neuronal lipofuscinosis even in the oldest $G R N^{-/-}$mice, suggesting that other factors may also contribute to the propensity for lipofuscin accumulation.

Interestingly, the same pattern of regional selective vulnerability seen in $G R N^{-1-}$ mice was also observed for $G R N^{+/+}$and $G_{R N^{+/-}}$mice, suggesting that neurons in these regions are in general more vulnerable to the normal aging process. These similarities in relative regional vulnerability support the use of $G R N^{-1-}$ mice as models of accelerated aging. 
To further examine the role that progranulin plays in the CNS, we examined progranulin levels in the brains of another mouse model of lipofuscinosis, which in this case has been genetically induced by cathepsin D deficiency. ${ }^{26}$ Progranulin mRNA and protein levels were significantly increased in the context of robust lipofuscinosis observed in cathepsin D knockout mice. These data further support a neurotrophic role for progranulin in the CNS, which may also be up-regulated during cellular stress or aging.

Interestingly, $G R N^{-1-}$ mice have a number of striking neuropathological similarities to an established murine model of aging. ${ }^{38}$ Senescence-accelerated mice (SAM) strain P10 (SAMP10) were also characterized by progressive accumulation of ubiquitin-positive neuronal lipofuscin, which occurred at 7 months, increased with age, and affected the limbic-related region; these features are also seen in $\mathrm{GRN}^{-1-}$ mice. The same age-related pathology was milder and occurred later in control strains (SAM1 and $\mathrm{C} 57 \mathrm{BL}$ ) used by Shimada et al. ${ }^{38}$ The abnormal accumulation of lipofuscin in SAMP10 mice was attributed to age-associated decreases in proteasome activity, specifically in those limbic-related regions that were vulnerable to ubiquitin pathology. Similar to $G R N^{-1-}$ mice, SAMP10 mice were also shown in a separate study to have extensive gliosis characterized by changes in microglial morphology and numbers. ${ }^{39}$ Pathological similarities between $G R N^{-1-}$ and SAMP10 mice suggest that they may share a common underlying abnormality. Consistent with this idea, SAMP10 mice have a mutation in the fibroblast growth factor (FGF1) gene, resulting in the absence of normal FGF1. ${ }^{40}$ This raises the possibility that PGRN and FGF1 may have similar or overlapping biological functions and that loss of either protein could result in evidence of accelerated aging, such as increased lipofuscinosis.

Some features of $\mathrm{GRN}^{-1-}$ mice such as tissue vacuolation (in the habenular nucleus or hippocampus) have not been described in SAMP10 mice, although these may have been overlooked. Since the discovery of SAMP10 mice in 1992, they have been extensively studied ${ }^{41}$ and are reported to have numerous abnormalities including behavioral changes, gross brain atrophy, neuronal loss, synaptic loss, dendrite retraction, decreased spine density, and neuronal DNA damage. Similar studies are also warranted to further characterize $\mathrm{GRN}^{-1-}$ mice, which will enable more direct comparison of these accelerated senescence models.

Analysis of an aged series of $G R N^{-1-}$ mice (1 to 23 months) enabled the chronological sequence of pathological events to be determined. The lack of any pathological differences among the youngest mice (1 month) indicates that PGRN is not absolutely essential for brain development or early stages of life. It was only at 7 months that pathological changes in $\mathrm{GRN}^{-/-}$mice were identified. These included neuronal lipofuscinosis, microglial changes, and tissue vacuolation. At 12 months astrocytic changes were also detected. At their respective onset, neuronal, microglial, and astrocytic changes were fairly subtle but then increased in severity in an agedependent manner, until they were fulminant by 23 months, at which point other signs of neurodegeneration (focal neuronal loss and extraneuronal lipofuscin) were also evident. Earlier studies indicated a neurotrophic role for PGRN, ${ }^{16,42}$ supported by more recent studies showing that PGRN enhances neuronal survival and neurite outgrowth. ${ }^{17} \mathrm{~A}$ higher rate of neuronal lipofuscin accumulation in $\mathrm{GRN}^{-1-}$ mice is also consistent with a neurotrophic role for PGRN, especially considering that the rate of lipofuscin formation has been shown to be negatively correlated with the life expectancy of postmitotic cells, ie, the higher the rate, the shorter the lifespan of the cell. ${ }^{34}$

With this evidence it is tempting to speculate how PGRN knockdown results in the neurodegeneration in $G R N^{-1-}$ mice (Figure 7). At around 7 months the lack of PGRN and its neurotrophic support ${ }^{16,17,41}$ results in the progressive accumulation of neuronal lipofuscin, which in turn causes cellular stress. ${ }^{34}$ Given the ability for microglia to sense and respond to neuronal distress, ${ }^{35,43} \mathrm{mi}-$ croglia in the vicinity of neurons containing lipofuscin become activated as indicated by morphological transformations. At 12 months, the continual accumulation of lipofuscin and increased cellular stress results in further microglial activation, which in turn signals astrocytic activation, as indicated by increased GFAP expression. Despite support from glial cells, the accumulation of lipofuscin and cellular stress eventually results in neuronal cell death and the phagocytosis or expulsion of lipofuscin by microglia or into the extracellular space, respectively.

This hypothetical scenario in which microglial activation is a secondary event to neuronal distress is probably overly simplistic. One of the complicating issues is that PGRN along with its potential role as a neurotrophic factor is also involved in the process of inflammation. Full-length PGRN is thought to be anti-inflammatory, whereas proteolytically cleaved GRNs have proinflammatory properties. ${ }^{4}$ With PGRN expression being relatively high in microglia, it is also possible that the changes witnessed in $G R N^{-1-}$ mice could be caused by microglial dysfunction due to a lack of microglial PGRN. The pathology in $G R N^{-1-}$ mice exhibited a degree of regional selective vulnerability, which may favor the former hypothesis (Figure 7), as one might expect all microglia to be affected more or less equally. At this stage these ideas are speculative and would benefit from the generation of cell-type specific PGRN knockdown models to distinguish the role of microglial from neuronal derived PGRN

In conclusion, this is the first study to detail the neuropathological features throughout the lifespan of GRNdeficient mice. Although these mice did not develop TDP43-positive inclusions typical of FTLD-U with GRN mutations, the pathological characteristics of $G R N^{-1-}$ mice suggest a novel biological role for PGRN in successful aging. This is compatible with the previously described role of PGRN as a neurotrophic factor required for long-term neuronal survival. GRN ${ }^{-1-}$ mice could not only be used to further explore the biology of PGRN, but their similarities to SAMP10 mice also suggest they might also be used as a tool to study pathological premature aging. Given that severe neurodegeneration was only noted in the oldest $\mathrm{GRN}^{-1-}$ mice at 23 months of age, 
inducing cellular stress (eg, pharmacologically or physically) in younger $\mathrm{GRN}^{-\prime-}$ mice may accelerate neurodegeneration. Exposing $\mathrm{GRN}^{+/-}$mice to cellular stress may be a potential strategy for inducing neurodegenerative features, similar to those seen in $G R N^{-\prime-}$ mice or even those in individuals with GRN mutations. Further studies in $G_{R N}{ }^{-1-}$ mice, especially those that correlate pathological changes with behavioral abnormalities, are warranted.

\section{Acknowledgments}

We acknowledge the valuable histological support of Monica Casey-Castanedes, Virginia Phillips, and Linda Rousseau.

\section{References}

1. Daniel R, Daniels E, He Z, Bateman A: Progranulin (acrogranin/PC cell-derived growth factor/granulin-epithelin precursor) is expressed in the placenta, epidermis, microvasculature, and brain during murine development. Dev Dyn 2003, 227:593-599

2. Avrova AO, Stewart HE, De Jong WD, Heilbronn J, Lyon GD, Birch PR: A cysteine protease gene is expressed early in resistant potato interactions with Phytophthora infestans. Mol Plant Microbe Interact 1999, 12:1114-1119

3. Bhandari V, Palfree RG, Bateman A: Isolation and sequence of the granulin precursor cDNA from human bone marrow reveals tandem cysteine-rich granulin domains. Proc Natl Acad Sci USA 1992 89:1715-1719

4. Ahmed Z, Mackenzie IR, Hutton ML, Dickson DW: Progranulin in frontotemporal lobar degeneration and neuroinflammation. J Neuroinflammation 2007, 4:7

5. He Z, Bateman A: Progranulin (granulin-epithelin precursor, PC-cellderived growth factor, acrogranin) mediates tissue repair and tumorigenesis. J Mol Med 2003, 81:600-612

6. Baker M, Mackenzie IR, Pickering-Brown SM, Gass J, Rademakers R, Lindholm C, Snowden J, Adamson J, Sadovnick AD, Rollinson S, Cannon A, Dwosh E, Neary D, Melquist S, Richardson A, Dickson D, Berger Z, Eriksen J, Robinson T, Zehr C, Dickey CA, Crook R, McGowan E, Mann D, Boeve B, Feldman H, Hutton M: Mutations in progranulin cause tau-negative frontotemporal dementia linked to chromosome 17. Nature 2006, 442:916-919

7. Cruts M, Kumar-Singh S, Van Broeckhoven C: Progranulin mutations in ubiquitin-positive frontotemporal dementia linked to chromosome 17q21. Curr Alzheimer Res 2006, 3:485-491

8. Coppola G, Karydas A, Rademakers R, Wang Q, Baker M, Hutton M, Miller BL, Geschwind DH: Gene expression study on peripheral blood identifies progranulin mutations. Ann Neurol 2008, 64:92-96

9. Ghidoni R, Benussi L, Glionna M, Franzoni M, Binetti G: Low plasma progranulin levels predict progranulin mutations in frontotemporal lobar degeneration. Neurology 2008, 71:1235-1239

10. Finch N, Baker M, Crook R, Swanson K, Kuntz K, Surtees R, Bisceglio G, Rovelet-Lecrux A, Boeve B, Petersen RC, Dickson DW, Younkin SG, Deramecourt V, Crook J, Graff-Radford NR, Rademakers R: Plasma progranulin levels predict progranulin mutation status in frontotemporal dementia patients and asymptomatic family members. Brain 2009, 132:583-591

11. Mackenzie IR: The neuropathology and clinical phenotype of FTD with progranulin mutations. Acta Neuropathol 2007, 114:49-54

12. Neumann M, Sampathu DM, Kwong LK, Truax AC, Micsenyi MC, Chou TT, Bruce J, Schuck T, Grossman M, Clark CM, McCluskey LF, Miller BL, Masliah E, Mackenzie IR, Feldman H, Feiden W, Kretzschmar HA, Trojanowski JQ, Lee VM: Ubiquitinated TDP-43 in frontotemporal lobar degeneration and amyotrophic lateral sclerosis. Science 2006, 314:130-133

13. Josephs KA, Ahmed Z, Katsuse O, Parisi JF, Boeve BF, Knopman DS, Petersen RC, Davies P, Duara R, Graff-Radford NR, Uitti RJ,
Rademakers R, Adamson J, Baker M, Hutton ML, Dickson DW: Neuropathologic features of frontotemporal lobar degeneration with ubiquitin-positive inclusions with progranulin gene (PGRN) mutations. J Neuropathol Exp Neurol 2007, 66:142-151

14. Mackenzie IR, Baker M, Pickering-Brown S, Hsiung GY, Lindholm C, Dwosh E, Gass J, Cannon A, Rademakers R, Hutton M, Feldman HH: The neuropathology of frontotemporal lobar degeneration caused by mutations in the progranulin gene. Brain 2006, 129:3081-3090

15. Mukherjee O, Pastor P, Cairns NJ, Chakraverty S, Kauwe JS, Shears S, Behrens MI, Budde J, Hinrichs AL, Norton J, Levitch D, TaylorReinwald L, Gitcho M, Tu PH, Tenenholz Grinberg L, Liscic RM, Armendariz J, Morris JC, Goate AM: HDDD2 is a familial frontotemporal lobar degeneration with ubiquitin-positive, tau-negative inclusions caused by a missense mutation in the signal peptide of progranulin. Ann Neurol 2006, 60:314-322

16. Daniel R, He Z, Carmichael KP, Halper J, Bateman A: Cellular localization of gene expression for progranulin. J Histochem Cytochem 2000, 48:999-1009

17. Van Damme $P$, Van Hoecke A, Lambrechts D, Vanacker $P$, Bogaert E, van Swieten J, Carmeliet P, Van Den Bosch L, Robberecht W: Progranulin functions as a neurotrophic factor to regulate neurite outgrowth and enhance neuronal survival. J Cell Biol 2008, 181:37-41

18. Suzuki M, Yoshida S, Nishihara M, Takahashi M: Identification of a sex steroid-inducible gene in the neonatal rat hypothalamus. Neurosci Lett 1998, 242:127-130

19. Kayasuga Y, Chiba S, Suzuki M, Kikusui T, Matsuwaki T, Yamanouchi K, Kotaki H, Horai R, Iwakura $Y$, Nishihara M: Alteration of behavioural phenotype in mice by targeted disruption of the progranulin gene. Behav Brain Res 2007, 185:110-118

20. Chiba S, Matsuwaki T, Yamanouchi K, Nishihara M: Alteration in anxiety with relation to the volume of the locus ceruleus in progranulin-deficient mice. J Reprod Dev 2009, 55:518-522.

21. Dormann D, Capell A, Carlson AM, Shankaran SS, Rodde R, Neumann M, Kremmer E, Matsuwaki T, Yamanouchi K, Nishihara M, Haass C: Proteolytic processing of TAR DNA binding protein- 43 by caspases produces C-terminal fragments with disease defining properties independent of progranulin. J Neurochem 2009, 110:1082-1094

22. Margolis G, Pickett JP: New applications of the Luxol fast blue myelin stain. Lab Invest 1956, 5:459-474

23. Ghandour MS, Langley OK, Vincendon G, Gombos G, Filippi D, Limozin N, Dalmasso D, Laurent G: Immunochemical and immunohistochemical study of carbonic anhydrase II in adult rat cerebellum: a marker for oligodendrocytes. Neuroscience 1980, 5:559-571

24. Ahmed Z, Shaw G, Sharma VP, Yang C, McGowan E, Dickson DW: Actin-binding proteins coronin-1a and IBA-1 are effective microglial markers for immunohistochemistry. J Histochem Cytochem 2007, 55:687-700

25. Dickson DW, Crystal H, Mattiace LA, Kress Y, Schwagerl A, KsiezakReding $H$, Davies P, Yen SH: Diffuse Lewy body disease: light and electron microscopic immunocytochemistry of senile plaques. Acta Neuropathol 1989, 78:572-584

26. Saftig $P$, Hetman M, Schmahl W, Weber K, Heine L, Mossmann H, Koster A, Hess B, Evers M, von Figura K, Peters C: Mice deficient for the lysosomal proteinase cathepsin $\mathrm{D}$ exhibit progressive atrophy of the intestinal mucosa and profound destruction of lymphoid cells. EMBO J 1995, 14:3599-3608

27. Cook C, Zhang YJ, Xu YF, Dickson DW, Petrucelli L: TDP-43 in neurodegenerative disorders. Expert Opin Biol Ther 2008, 8:969-978

28. Double KL, Dedov VN, Fedorow H, Kettle E, Halliday GM, Garner B, Brunk UT: The comparative biology of neuromelanin and lipofuscin in the human brain. Cell Mol Life Sci 2008, 65:1669-1682

29. Peters A, Palay SL, Webster HD: The fine structure of the nervous system: neurons and their supporting cells. New York, Oxford University Press, 1991 pp 34-38

30. Zhang YJ, Xu YF, Dickey CA, Buratti E, Baralle F, Bailey R, PickeringBrown S, Dickson D, Petrucelli L: Progranulin mediates caspasedependent cleavage of TAR DNA binding protein-43. J Neurosci 2007, 27:10530-10534

31. Pereson S, Wils H, Kleinberger G, McGowan E, Vandewoestyne M, Van Broeck B, Joris G, Cuijt I, Deforce D, Hutton M, Van Broeckhoven C, Kumar-Singh S: Progranulin expression correlates with dense-core amyloid plaque burden in Alzheimer disease mouse models. J Pathol 2009, 219:173-181

32. Yin F, Banerjee R, Thomas B, Zhou P, Qian L, Jia T, Ma X, Ma Y, 
ladecola C, Beal MF, Nathan C, Ding A: Exaggerated inflammation, impaired host defense, and neuropathology in progranulin-deficient mice, J Exp Med 2009, 207:117-128, S111-114

33. Jolly RD, Palmer DN, Dalefield RR: The analytical approach to the nature of lipofuscin (age pigment). Arch Gerontol Geriatr 2002, 34:205-217

34. Jung T, Bader N, Grune T: Lipofuscin: formation, distribution, and metabolic consequences. Ann NY Acad Sci 2007, 1119:97-111

35. Bianco IH, Wilson SW: Review. The habenular nuclei: a conserved asymmetric relay station in the vertebrate brain, Philos Trans R Soc Lond B Biol Sci 2009, 364:1005-1020

36. Streit WJ: Microglial response to brain injury: a brief synopsis. Toxicol Pathol 2000, 28:28-30

37. Streit WJ: Microglia and the response to brain injury. Ernst Schering Res Found Workshop 2002, 11-24

38. Shimada A, Keino H, Kawamura N, Chiba Y, Hosokawa M: Limbic structures are prone to age-related impairments in proteasome activity and neuronal ubiquitinated inclusions in SAMP10 mouse: a model of cerebral degeneration. Neuropathol Appl Neurobiol 2008, 34:33-51

39. Kumagai N, Chiba $Y$, Hosono M, Fujii M, Kawamura N, Keino $H$ Yoshikawa K, Ishii S, Saitoh Y, Satoh M, Shimada A, Hosokawa M: Involvement of pro-inflammatory cytokines and microglia in an ageassociated neurodegeneration model, the SAMP10 mouse. Brain Res 2007, 1185:75-85

40. Carter TA, Greenhall JA, Yoshida S, Fuchs S, Helton R, Swaroop A Lockhart DJ, Barlow C: Mechanisms of aging in senescence-accelerated mice. Genome Biol 2005, 6:R48

41. Takeda T: Senescence-accelerated mouse (SAM) with special references to neurodegeneration models. SAMP8 and SAMP10 mice. Neurochem Res 2009, 34:639-659

42. Matzilevich DA, Rall JM, Moore AN, Grill RJ, Dash PK: High-density microarray analysis of hippocampal gene expression following experimental brain injury. J Neurosci Res 2002, 67:646-663

43. Streit WJ: Microglia as neuroprotective, immunocompetent cells of the CNS. Glia 2002, 40:133-139 